\title{
Great Plains Hydroclimate Variability: The View from North American Regional Reanalysis
}

\author{
Alfredo Ruiz-BARRAdas \\ Department of Atmospheric and Oceanic Science, University of Maryland, College Park, College Park, Maryland \\ SUMANT NigAm \\ Department of Atmospheric and Oceanic Science, and the Earth System Science Interdisciplinary Center, University of Maryland, \\ College Park, College Park, Maryland
}

(Manuscript received 4 April 2005, in final form 9 August 2005)

\begin{abstract}
Interannual variability of warm-season rainfall over the Great Plains is analyzed using the recently released North American Regional Reanalysis (NARR). The new dataset differs from its global counterparts in the additional assimilation of precipitation and radiances. This along with the use of a more comprehensive land surface model in generation of NARR offers the prospect of obtaining improved estimates of surface hydrologic and near-surface meteorological fields.

NARR's representation of hydroclimate is used to weigh in on the authors' recent finding of the dominance of large-scale moisture flux convergence over evaporation in accounting for Great Plains precipitation variations. Evaporation estimates are notoriously uncertain and, while the NARR ones are not assured to be realistic, they are more constrained than those diagnosed before from inline and offline assessments.

NARR's portrayal of warm-season hydroclimate variability corroborates the importance of remote water sources in generation of Great Plains precipitation variability and supports the authors' claim that some state-of-the-art atmosphere/land surface models vigorously recycle precipitation, erroneously, at least in context of Great Plains interannual variability. These very models have been key to recent claims of strong coupling between soil moisture and precipitation.
\end{abstract}

\section{Introduction}

The authors have recently concluded an analysis of Great Plains hydroclimate variability, focusing on the anomalous atmospheric water balance in the warmseason months in both nature and state-of-the-art atmospheric model simulations (Ruiz-Barradas and Nigam 2005; hereafter RBN). The structure of precipitation and the role of local and remote water sourcesevaporation and moisture fluxes, respectively-in producing it were examined. Our main finding of the dominance of remote sources over local ones in nature and quite the opposite in model simulations [National Center for Atmospheric Research (NCAR) Community Atmosphere Model version 3.0 (CAM3.0) and National Aeronautics and Space Administration (NASA) Sea-

Corresponding author address: Alfredo Ruiz-Barradas, University of Maryland, College Park, 3405 Computer and Space Sciences Bldg., College Park, MD 20742-2425.

E-mail: alfredo@atmos.umd.edu
sonal-to-Interannual Precipitation Project (NSIPP)] was tempered by the uncertainty in the distribution of hydroclimate observations, especially evaporation.

Precipitation is generally the best measured of the analyzed fields (precipitation, evaporation, and moisture fluxes), with station- and satellite-based distributions in good agreement over North America. Moisture fluxes, in contrast, depend on the horizontal and vertical structure of circulation and moisture, that is, on observations and sampling that are not always adequate even in densely observed regions such as the Great Plains. Reanalysis-based moisture fluxes are thus, to an extent, dependent on the forecast model's first-guess fields, that is, on the model's physics and data assimilation strategy. But the least constrained, and thus, the most uncertain of the atmospheric water balance terms is evaporation. There are no regional-to-continentalscale measurements of evaporation, soil moisture, and surface/subsurface runoff that can serve to constrain the evaporation diagnosis.

Since the submission of our paper (RBN), however, 
the National Centers for Environmental Prediction (NCEP) have released the North American Regional Reanalysis dataset (NARR: Mesinger et al. 2004; Mitchell et al. 2004). Salient features of NARR include the direct, additional assimilation of precipitation and radiances, high spatial and temporal resolution, and the use of an improved land surface model Noah (Ek et al. 2003). The precipitation representation is very realistic in NARR, that is, the assimilation strategy has been effective; precipitation assimilation has also been beneficial for other meteorological fields. But even more importantly, NARR allows the land surface model to interact with realistic precipitation; that is, the land surface model both influences and is influenced by precipitation. Note that the influence is only one-way in the offline evaporation diagnoses where hydrologic models are driven by observed surface temperature and precipitation (Huang et al. 1996; Dirmeyer and Tan 2001).

The present study is motivated by the availability of surface hydrologic and near-surface meteorological fields from an improved, comprehensive land surface model that interacts fully with realistic precipitation (and meteorological fields). Potentially improved estimates of evaporation and moisture fluxes from NARR are used to reassess the nature of the atmospheric water balance over the Great Plains in context of warmseason interannual variability. The brief analysis closely mirrors the RBN study, whose precipitation-centric analysis strategy proves advantageous in fostering intercomparison with NARR hydroclimate in view of NARR's successful assimilation of precipitation.

\section{Datasets}

The North American Regional Reanalysis is a longterm, consistent, data-assimilation-based, climate data suite for North America (http://wwwt.emc.ncep. noaa.gov/mmb/rreanl/; Mesinger et al. 2004). The regional reanalysis is produced at high spatial and temporal resolutions (32 km, 45 layer, and 3 hourly) and spans a period of 25 years from October 1978 to December 2003; it is based on the April 2003 frozen version of NCEP's mesoscale Eta forecast model and its data assimilation system (EDAS). As noted before, NARR assimilates precipitation, unlike reanalyses of its global counterparts, NCEP-NCAR (Kalnay et al. 1996) and the 40-yr European Centre for MediumRange Weather Forecasts (ECMWF) Re-Analysis (ERA-40; http://www.ecmwf.int/products/data/archive/ descriptions/e4/). The assimilation is, in fact, successful, with downstream effects, including two-way interaction between precipitation and the improved land surface model (Ek et al. 2003; Mitchell et al. 2004).

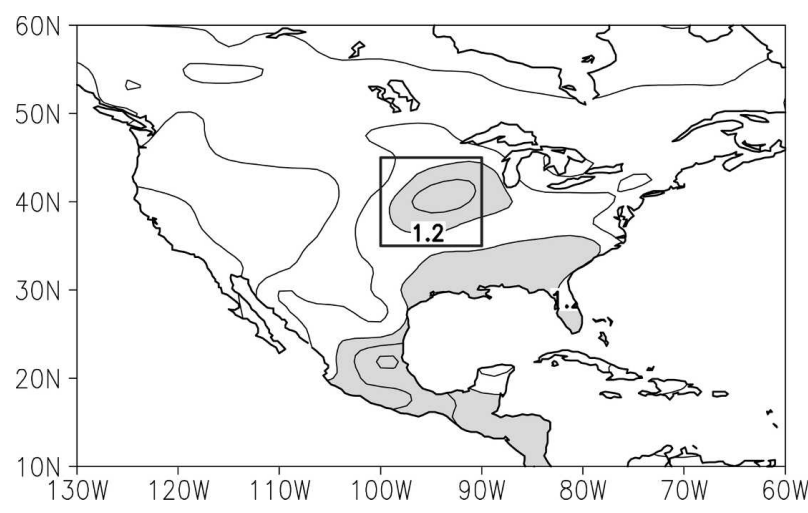

FIG. 1. Standard deviation of monthly precipitation anomalies during summer (June-August) in the NARR dataset for the 197998 period. Oceanic values are suppressed. Contour interval is 0.3 $\mathrm{mm}$ day $^{-1}$ and values greater than $1.2 \mathrm{~mm}$ day $^{-1}$ are shaded.

The dataset of choice for U.S.-Mexico precipitation is the NOAA/Climate Prediction Center's (CPC's) retrospective analysis of daily station data (http://www. cpc.ncep.noaa.gov/products/precip/realtime/retro. shtml; hereafter, referred as the U.S.-Mexico dataset), which was extensively used for validation in RBN. Moisture fluxes are calculated, as in RBN, by computing the mass-weighted vertical integral from the surface to $300 \mathrm{hPa}$; however, in interest of close comparisons, data from only those pressure levels that got reported in NCEP-NCAR reanalysis are used. Stationary fluxes refer to moisture transports by the monthly mean circulation, while transient ones refer to transports by the correlated submonthly time-scale fluctuations. For consistency with earlier analysis, NARR data has been interpolated to a $5^{\circ} \times 2.5^{\circ}$ grid, which is sufficient for resolving the regional-to-continental-scale regression patterns. The warm-season months of June, July, and August are the focus, as in RBN, but anomalies are computed here with respect to the shorter 1979-98 monthly climatology, the overlapping NARR period.

\section{Precipitation variability}

The distribution of warm-season precipitation variability is shown in Fig. 1; the standard deviation (SD) of monthly NARR precipitation anomalies is displayed. Because NARR assimilates U.S.-Mexico precipitation and because the assimilation is effective, the SD distribution is almost identical to that computed from U.S.Mexico data (Fig. 1a in RBN); both have a local maximum over the Great Plains.

The temporal variability of Great Plains precipitation is described using the areal average of monthly precipitation anomalies in the region encompassing the local 


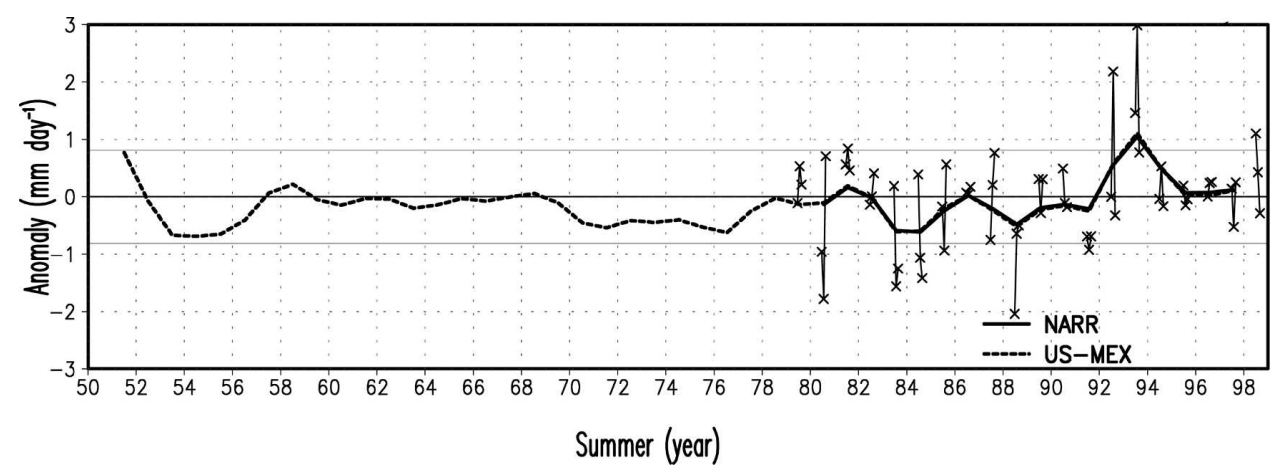

FIG. 2. GPP index anomalies in the warm season (June, July, and August) in the NARR dataset. Monthly values are marked by "x," while the smoothed index version obtained from a 1-2-1 averaging of the seasonal-mean anomalies is displayed using a solid line; horizontal lines mark the \pm 1 standard deviation $\left(\mathrm{SD}=0.81 \mathrm{~mm} \mathrm{day}^{-1}\right)$. For comparison, the smoothed index from the U.S.-Mexico station data is included (dashed line). Monthly warm-season correlation between NARR and U.S.-Mexico precipitation indices is 0.99 .

maximum in SD. The precipitation average in the $10^{\circ}$ latitude-longitude box $\left(35^{\circ}-45^{\circ} \mathrm{N}, 100^{\circ}-90^{\circ} \mathrm{W}\right.$; marked in Fig. 1) defines the Great Plains precipitation (GPP) index; the index from NARR is shown in Fig. 2. The early summer drought in 1988 and the 1993 summer floods over the Great Plains are nicely captured. The NARR and U.S.-Mexico-based indices are, not surprisingly, correlated at 0.99 at monthly time scales. The variability amplitudes are comparable also: JJA monthly standard deviation is $0.81 \mathrm{~mm} \mathrm{day}^{-1}$ in NARR and $0.86 \mathrm{~mm} \mathrm{day}^{-1}$ in the U.S.-Mexico dataset for the same 1979-98 period. NARR's success in assimilating precipitation is also manifest in the extensive overlap of the solid (NARR) and dashed (U.S.-Mexico) curves in Fig. 2, which are smoothed versions of the GPP index; smoothed indices are produced from the 1-2-1 smoothing of the summer-mean anomalies. ${ }^{1}$

\section{Convective and stratiform rainfall}

The convective and stratiform contributions to the smoothed GPP index are shown in Fig. 3; note that stratiform rain is also called large-scale condensation. Convective precipitation is quite significant in summer (Dai 2001), but the stratiform component is far from being negligible: Convective rainfall is stronger by a factor of 2 in NARR, but a bit weaker than the stratiform component in ERA-40. Interestingly, variations in stratiform rain are more consistent between the two datasets; the smoothed stratiform rainfall indices are correlated at 0.89 while the convective ones are corre-

\footnotetext{
${ }^{1}$ The smoothed index is thus based on the preceding, current, and subsequent summer means.
}

lated at 0.56. ERA-40 (and NCEP-NCAR) reanalyses exhibit an upward trend in Great Plains precipitation since the mid-1960s, as noted in RBN, for reasons that are unclear. The partitioning of convection depends on the model's horizontal resolution, among other things, so resolution differences could well account for some of the above-noted differences. The NARR data supports our assessment that many state-of-the-art atmospheric models are generating too little stratiform rainfall over the Great Plains in the warm-season months $(\mathrm{RBN}){ }^{2}$

\section{Great Plains precipitation linkages}

The NARR view of Great Plains precipitation variability, especially as manifest in the atmospheric water balance, is presented in this section, in much the same format as in RBN. The GPP index is regressed on monthly precipitation, stationary and transient moisture fluxes, and evaporation during the 1979-98 warmseason months; the corresponding regressions in RBN are over periods twice as long. The shorter analysis period here is, however, not an issue since it is not the structural correspondence of the fields as much as the relative importance of the anomalous water balance terms that we are after, as ascertained by computation of the RBN regressions in this period.

\footnotetext{
${ }^{2}$ Since submission, the Intergovernmental Panel on Climate Change's (IPCC's) twentieth-century climate simulations have been analyzed for the convective/ stratiform partitioning of warmseason precipitation over the Great Plains. The majority of the examined models (five out of eight) show very little stratiform rainfall in accord with our claim, but a few (three) do produce it in significant amounts; with one even producing more stratiform than convective rain.
} 


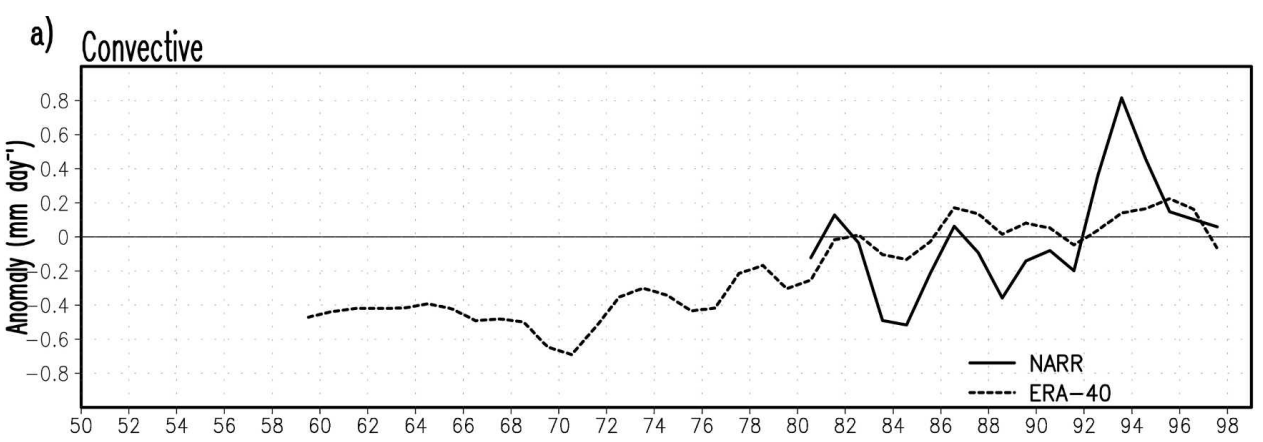

b) Stratiform (Large-scale condensation)

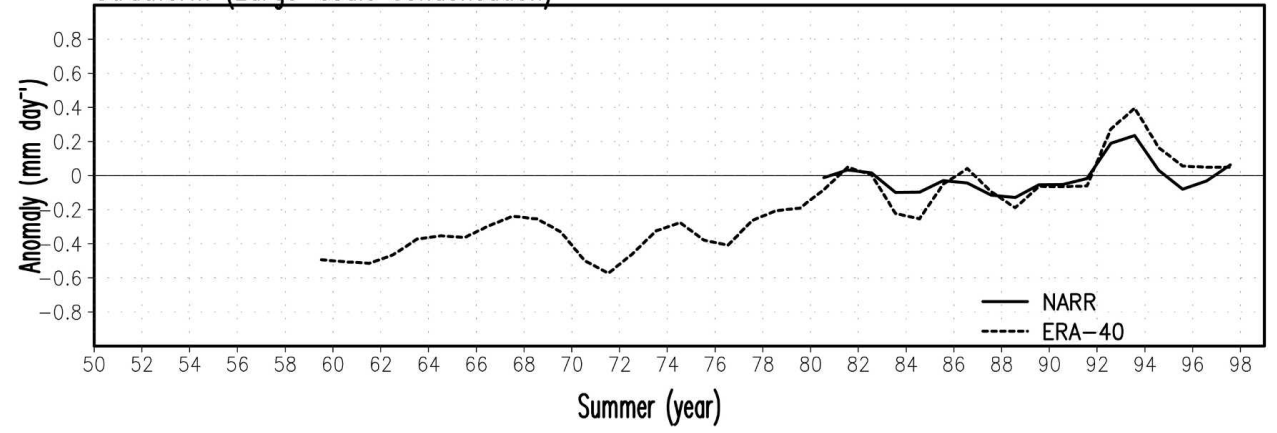

FIG. 3. (a) Convective and (b) stratiform contributions to the GPP index variations in the NARR dataset during the warm season. The contributions are smoothed as described earlier. Solid lines denote the contributions in the NARR dataset, which begins in 1979, while dashed lines denote contributions in ERA-40 reanalysis, which starts in 1958. Note the synchronous variations between both datasets for any particular contribution.

\section{a. Precipitation}

The precipitation regression is shown in Fig. 4a, principally to define the amplitude of variability: 1.0-1.2 $\mathrm{mm}$ day $^{-1}$ over the core region. While the coherent structure over the Great Plains is not surprising given the GPP index definition, it is noteworthy that positive rainfall anomalies there are not generated at the expense of rainfall in adjoining or remote continental regions.

\section{b. Moisture fluxes}

The stationary and transient moisture flux regressions are shown in Figs. 4b-c. ${ }^{3}$ Associated moisture flux

\footnotetext{
${ }^{3}$ The mass-weighted, vertically averaged stationary and transient moisture fluxes are computed over slightly different pressure layers: the stationary component was integrated over the surfaceto-300-hPa layer using NARR data at the NCEP reanalysis pressure levels. The transient component was computed as a residual, by subtracting the diagnosed stationary flux from the total NARR flux (in the deeper surface-to-25-hPa layer), since the latter was readily available in the NARR data archives. Inclusion of the extra 300-25-hPa layer is of little consequence for moisture flux diagnosis given the rapid falloff of moisture with height, but in-
}

convergence is also shown in these panels using contours; the contouring interval, $0.3 \mathrm{~mm} \mathrm{day}^{-1}$, is the same as that used in the precipitation regressions.

Great Plains precipitation variability in NARR is largely supported by the convergence of stationary moisture flux: A coherent, anticyclonic circulation sweeps moisture northward from the Gulf of Mexico and the Caribbean Seas. The anomalous circulation, reflecting displacement and/or expansion of the climatological Bermuda high, is evident also in the regressions obtained with ERA-40 data (Fig. 6e in RBN), but not in the NCEP-NCAR reanalysis ones (Fig. 6d in $\mathrm{RBN}$ ). A weaker connection to the Pacific, via westerly fluxes over the southwestern states, is a feature present in both global and regional reanalyses.

Convergence of stationary moisture flux apparently accounts for up to three-fourths of the rainfall over the Great Plains in NARR, in accord with the ERA-40-

tegration over all NARR pressure levels, especially the additional ones in the lower troposphere in calculation of the total flux could result in slight overestimation of the transient component. (A direct, albeit tedious, computation of the transient moisture flux is currently underway.) 

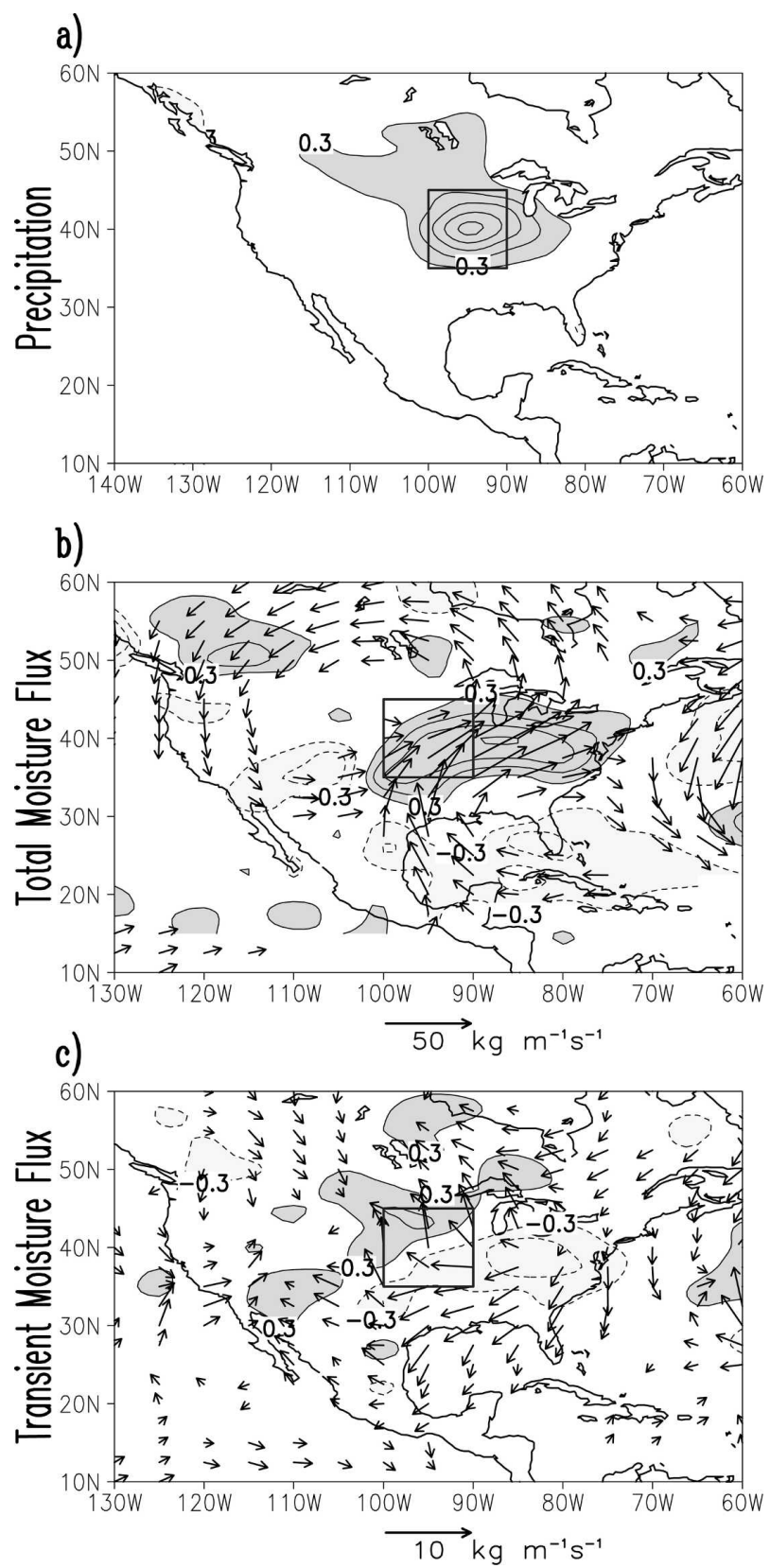

FIG. 4. Warm-season regressions of the GPP index on (a) precipitation, (b) stationary moisture fluxes, and (c) transient moisture fluxes; moisture flux convergence is also displayed in (b), (c). Moisture fluxes and corresponding flux convergences are vertically integrated ( $300 \mathrm{hPa}$-surface). Both precipitation and moisture flux convergence are contoured with the same interval $(0.3$ $\mathrm{mm}$ day $^{-1}$ ); dark (light) shading denotes areas of positive (negative) rainfall and moisture flux convergence (divergence) in excess of $0.3 \mathrm{~mm}$ day $^{-1}$ magnitude; the zero contour is omitted in all panels. The vector scale for fluxes is shown at the bottom of each panel; note the 5-times-larger scale in the display of the stationary component.

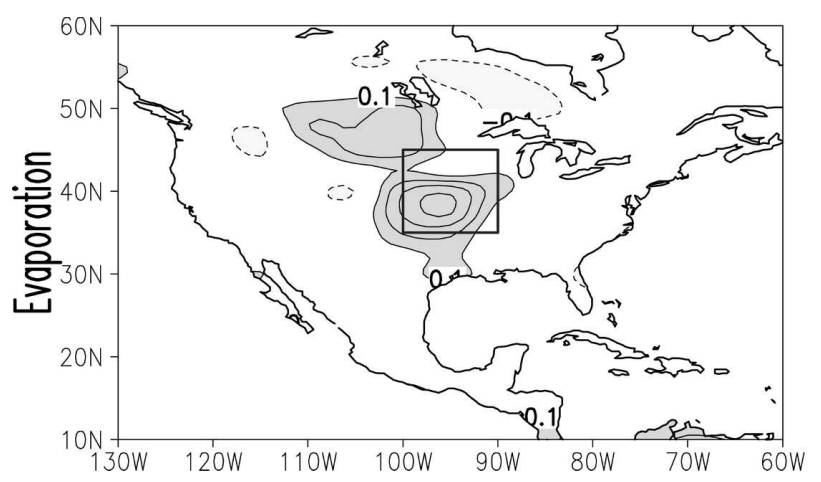

FIG. 5. Warm-season regressions of the GPP index on evaporation (surface latent heat flux). The contour interval and shading threshold is $0.1 \mathrm{~mm} \mathrm{day}^{-1}$, with positive (negative) values shaded dark (light); the zero contour is omitted.

based assessment (RBN). The transient moisture fluxes are about one-fifth in magnitude, but the convergence they produce is comparable. Fluxes are westward and divergent over the eastern United States and northwestward and convergent over the northern Great Plains; the convergence in the northwest corner of the $10^{\circ}$ box is, evidently, significant. Transient moisture flux in NARR is also similar to its ERA-40 counterpart (Fig. 6g in RBN) despite the period differences of the two regressions; the overestimation of transient fluxes here (cf. footnote 2) may thus be marginal.

\section{c. Evaporation}

The atmospheric water balance term in need of most refinement, especially on regional-to-continental scales, is evaporation, and NARR offers the prospect for its best-to-date diagnosis, for reasons discussed earlier. This entire analysis is, in some sense, driven by the curiosity to know how this field is represented in NARR in context of Great Plains hydroclimate variability. As noted earlier, RBN's finding of the importance of stationary fluxes in supplying moisture for Great Plains precipitation variability leaned heavily on the offline diagnosis of evaporation. RBN's indictment of NCAR CAM3.0 and NASA NSIPP atmospheric land surface models for generating precipitation variability from local evaporation would thus be in some jeopardy if the GPP index regressions on NARR evaporation turned out to be much larger than the previously obtained evaporation regressions (Figs. 8a-d in $\mathrm{RBN}$ ). The NARR evaporation regressions are contoured in Fig. 5 with the same interval as in RBN's Fig. 8 ; note that the interval, $0.1 \mathrm{~mm} \mathrm{day}{ }^{-1}$, is 3 times smaller than the one used to contour precipitation or moisture flux convergence in Fig. 4. 
The NARR evaporation anomalies are $\sim 0.3 \mathrm{~mm}$ day $^{-1}$ whereas the accompanying Great Plains precipitation variations are $\sim 1.0 \mathrm{~mm}$ day $^{-1}$; the evaporation contribution is thus no more than a third, in line with RBN findings. NARR evaporation is, in fact, quite comparable in magnitude to the offline-produced estimate (Dirmeyer and Tan 2001; Fig. 8b in RBN) and to its NCEP-NCAR reanalysis counterpart (Fig. 8c in $\mathrm{RBN})$.

\section{Concluding remarks}

The North American Regional Reanalysis provides a valuable, independent analysis of Great Plains hydroclimate variability. The successful assimilation of precipitation should positively influence land-atmosphere interaction and resulting hydroclimate. NARR's moisture fluxes and evaporation are used to ascertain the robustness of our findings on the nature of anomalous atmospheric water balance during warm-season precipitation variability over the Great Plains (RuizBarradas and Nigam 2005).

NARR's portrayal of warm-season hydroclimate variability corroborates the importance of remote water sources in generation of Great Plains precipitation variability and buttresses our claim that some state-ofthe-art atmosphere/land surface models [NCAR CAM3.0, NASA NSIPP, and NOAA/Geophysical Fluid Dynamics Laboratory Climate Model (GFDL) version 2.1 (CM2.1)] ${ }^{4}$ vigorously recycle precipitation erroneously-at least, in context of Great Plains interannual variability.

Interestingly, these very models (or their earlier versions) have been key to recent claims of strong coupling between soil moisture and precipitation, or "hot spots" (Koster et al. 2004). The claims are based on the Global Land-Atmosphere Coupling Experiment (GLACE; http:/glace.gsfc.nasa.gov) where coupling strength in 12 atmosphere/land surface models was analyzed. There is evidently considerable scatter in the strength of landatmosphere coupling in the GLACE models, especially over the central United States (cf. Fig. 1 in Koster et al. 2004). Surprisingly, the GLACE conclusion regarding hot spots is drawn by averaging the sensitivities of 12 models. The 12-model average is, of course, easily impacted by the large signals of a few models - the case in GLACE-making the multimodel average unrepresen-

\footnotetext{
${ }^{4}$ The first two models were analyzed in RBN. The NOAA/ GFDL CM2.1 model also exhibits similar behavior as shown by a recent analysis of its Atmospheric Model Intercomparison Project (AMIP) and IPCC's climate of the twentieth-century simulations.
}

tative of the analyzed model population. This very important feature of the GLACE finding - that the majority of the models ( 9 out of 12) do not support the hot spot hypothesis over the central United States-did not find prominence in the Koster et al. paper.

Our finding on "overcooking" of land-atmosphere interactions in these models is consistent with GLACE results pertaining to these models but not supportive of the drawn conclusion on strong coupling. These models are in the minority group (one-fourth of the population) but wield undue influence on GLACE conclusions because of the use of the "average" statistic.

The apportioning of central U.S. precipitation into terrestrial (local) and oceanic (remote) water sources has also been investigated using the back-trajectory technique (Brubaker et al. 2001). The analysis was conducted using the NCEP-NCAR reanalysis, which has a well-known, large positive bias in summer precipitation over the southeastern United States (Trenberth and Guillemot 1998; Higgins et al. 1996). The impact of excess precipitation on regional low-level circulation and humidity must influence the back-trajectory calculations, rendering them somewhat suspect, especially as a corroborative reference for our findings.

Different representations of regional water cycle variability must have footprints in the land surface energy balance. An examination of the spatiotemporal structure of radiative fluxes and Bowen's ratio is currently underway to shed light on the causes of the dominance of evaporation over moisture flux transports in accounting for Great Plains precipitation variations in many state-of-the-art atmospheric general circulation models.

Acknowledgments. The authors acknowledge support of DOE-CCPP DEFG 0201ER63258, NASANSIPP NAG512417, and NSF ATM-0445136 grants. We thank Kingtse Mo for making the NARR dataset available to us, as well as Jiande Wang for preparing it.

The authors thank David Straus, Adam Schlosser, and another reviewer for their constructive remarks.

\section{REFERENCES}

Brubaker, K., P. A. Dirmeyer, A. Sudradjat, B. S. Levy, and F. Bernal, 2001: A 36-yr climatological description of the evaporative sources of warm-season precipitation in the Mississippi River basin. J. Hydrometeor., 2, 537-557.

Dai, A., 2001: Global precipitation and thunderstorm frequencies. Part I: Seasonal and interannual variations. J. Climate, 14, 1092-1111.

Dirmeyer, P. A., and L. Tan, 2001: A multi-decadal global landsurface data set of state variables and fluxes. COLA Tech. Rep. 102, 43 pp. [Available from the Center for Ocean- 
Land-Atmosphere Studies, 4041 Powder Mill Road, \#302, Calverton, MD 20705.]

Ek, M. B., K. E. Mitchell, Y. Lin, E. Rogers, P. Grunmann, V. Koren, G. Gayno, and J. D. Tarpley, 2003: Implementation of Noah land surface model advances in the National Centers for Environmental Prediction operational mesoscale Eta model. J. Geophys. Res., 108, 8851, doi:10.1029/2002JD003296.

Higgins, R. W., K. C. Mo, and S. D. Schubert, 1996: The moisture budget of the central United States in spring as evaluated from the NCEP/NCAR and the NASA/DAO reanalyses. Mon. Wea. Rev., 124, 939-963.

Huang, J., H. M. Van den Dool, and K. P. Georgarakos, 1996: Analysis of model-calculated soil moisture over the United States (1931-1993) and applications to long-range temperature forecasts. J. Climate, 9, 1350-1362.

Kalnay, E., and Coauthors, 1996: The NCEP/NCAR 40-Year Reanalysis Project. Bull. Amer. Meteor. Soc., 77, 437-471.

Koster, R., and Coauthors, 2004: Regions of strong coupling be- tween soil moisture and precipitation. Science, 305, 11381140

Mesinger, F., and Coauthors, 2004: NCEP North American regional reanalysis. Preprints, 15th Symp. on Global Change and Climate Variations, Seattle, WA, Amer. Meteor. Soc., CD-ROM, P1.1.

Mitchell, K., and Coauthors, 2004: NCEP completes 25-year North American Reanalysis: Precipitation assimilation and land surface are two hallmarks. GEWEX News, Vol. 14, No. 2, International GEWEX Project Office, Sliver Spring, MD, 9-12.

Ruiz-Barradas, A., and S. Nigam, 2005: Warm-season rainfall variability over the U.S. Great Plains in observations, NCEP and ERA-40 reanalyses, and NCAR and NASA atmospheric model simulations. J. Climate, 18, 1808-1830.

Trenberth, K. E., and C. J. Guillemot, 1998: Evaluation of the atmospheric moisture and hydrological cycle in the NCEP/ NCAR reanalyses. Climate Dyn., 14, 213-231. 